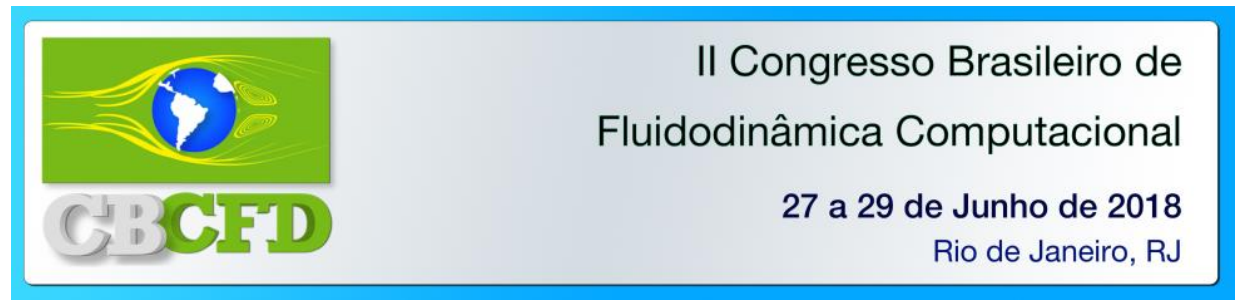

\title{
CFD ANALYSIS OF INFLUENCE OF INLET TEMPERATURE ON RISER FLUID CATALYTIC CRACKING CONVERSION
}

\author{
F. J. QUEIROZ1 ${ }^{1}$, B. C. C. SANTOS ${ }^{2}$, P. L. BARROS ${ }^{1,}$ \\ C. A. NASCIMENTO ${ }^{1}$, J. J. N. ALVES ${ }^{1}$ \\ ${ }^{1}$ Federal University of Campina Grande, Chemical Engineering Department \\ ${ }^{2}$ University of Campinas, School of Mechanical Engineering \\ Correspondence email address: josimar.queiroz@eq.ufcg.edu.br
}

\begin{abstract}
The catalytic cracking of petroleum is one of the most important processes in the oil industry. Through modeling and simulation of riser fluid catalytic cracking reactors using the software ANSYS ${ }^{\circledR}$ CFX, it was possible to analyze the production of gasoline, light gases and coke from the catalytic cracking of vacuum gas oil based on the 4-lumps kinetic model. The results obtained through computational simulations were compared with those of an industrial plant available in the literature, evaluating the reactor performance based on different variables. The influence of inlet temperature was studied. Moreover, the results showed that lower temperatures of feed inlet lead to a higher yield for gasoline whereas greater temperatures lead to a higher yield for light gases.
\end{abstract}

\section{INTRODUCTION}

Some of the main roles assigned to researchers are innovation and development of new processes and products as well as to continually improve what already exists. Fluid catalytic cracking has been one of the most important processes in oil the industry over the last decades; nevertheless, it is still being studied in order to achieve enhancements. Computational Fluid Dynamics (CFD) is a tool that allows those improvements and has a prominent role in several areas of engineering, e.g., modeling and simulation of fluid catalytic cracking (FCC) reactors. This work aims to model and simulate an industrial FCC unit using a 4-lump kinetic model and present a numerical study of the influence of inlet temperature on the conversion of vacuum gas oil (VGO) into gasoline, light gases, and coke.

\section{KINETIC MODELS}

Researchers have been developing kinetic models by grouping (or lumping) a large number of chemical compounds into smaller groups of pseudo-components, called lumps, which are distinct fractions with similar characteristics, such as molecular mass and boiling point. The 4-lumps kinetic model, proposed by Lee et al. in 1989, allows the prediction of coke formation. There are others models, even more elaborated, that are unable to predict it, this is one of the reasons why the model proposed by Lee et al. (1989) is one the most widespread. 

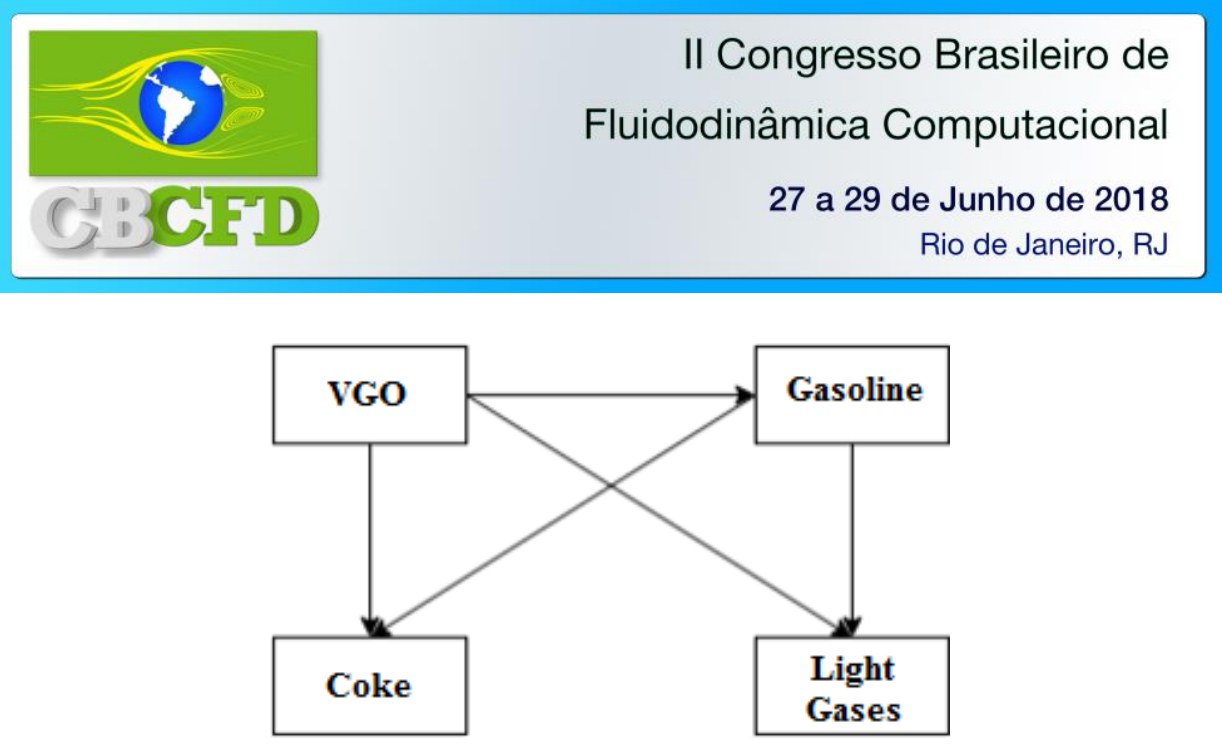

Figure 1 - 4-lump kinetic model

\section{MATHEMATICAL MODELING}

The process is governed by mass, energy and momentum equations. The consumption rates of a reagent $\mathrm{j}$ (VGO or gasoline for the kinetic model of 4-lumps) per unit volume of catalyst are calculated according to Eq. (1), proposed by Pachovsky and Wojciechowski (1971).

$$
-r_{j}=\Phi_{i} k_{j}\left(\frac{C_{j}}{C_{j_{o}}}\right)^{n} C_{j}
$$

For VGO cracking $\mathrm{n}$ is equal to $1, \mathrm{j}$ for gasoline cracking $\mathrm{n}$ is equal to 0 (Gupta and Rao, 2001). By using the Arrhenius Law, it is possible to calculate the variation of the constant of velocity $\left(k_{j}\right)$.

The catalyst activity term $\left(\Phi_{i}\right)$, based on the coke concentration in the catalyst, is calculated based on Eq. (2). The constants A and B of this equation are, respectively, 4,29 and 10,4, reported by Pitault et al. (1995). The mass fraction of coke varies along the reactor.

$$
\Phi_{i}=\frac{B+1}{B+e^{A \cdot w_{C}}}
$$

\section{SIMULATION}

The data of an industrial riser and the catalyst properties reported by Ali et al. (1997) were used in this paper as shown in Table 1.

Table 1 - Industrial FCC riser data and catalyst properties

\begin{tabular}{cc}
\hline Variable & Value \\
\hline Riser height $(\mathrm{m})$ & 33 \\
Riser diameter $(\mathrm{m})$ & 0,8 \\
Feed flow rate $\left(\mathrm{kg} \mathrm{s}^{-1}\right)$ & 20 \\
Catalyst flow rate $\left(\mathrm{kg} \mathrm{s}^{-1}\right)$ & 144 \\
Catalyst inlet temperature $(\mathrm{K})$ & 960 \\
Riser pressure $(\mathrm{atm})$ & 2,9 \\
Catalyst diameter $(\mu \mathrm{m})$ & 75 \\
Catalyst density $\left(\mathrm{kg} \mathrm{m}^{-3}\right)$ & 1200 \\
\hline
\end{tabular}

Source: Ali et al. (1997). 


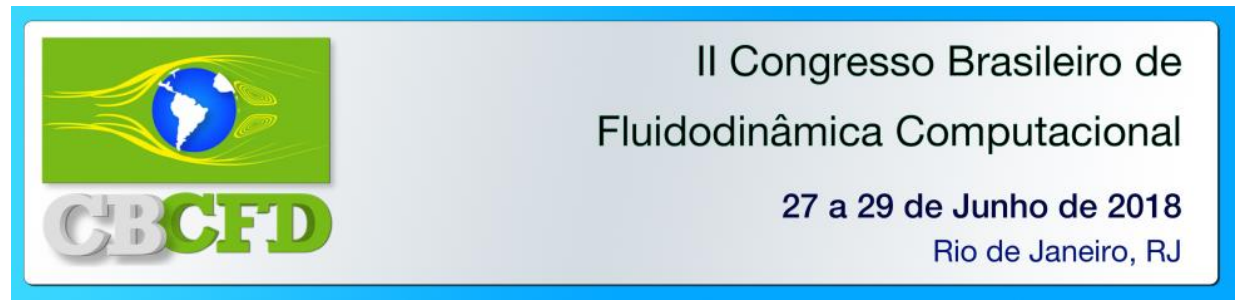

The reactor was assumed to be adiabatic. Regarding the VGO inlet temperature, its value was reported to be $494 \mathrm{~K}$. In this paper, it is presented a numerical study of the influence of the inlet temperature assuming different values within a 100 degrees range, also comparing the VGO conversion in the temperatures of $444 \mathrm{~K}, 469 \mathrm{~K}, 519 \mathrm{~K}$, and $544 \mathrm{~K}$. The cracking reactions are second order in VGO and first order in gasoline. The enthalpy, activation energy and preexponential factor values of the catalytic cracking reactions for the 4-lumps kinetic model used are available in the literature, respectively in Lee et al. (1989), Han and Chung (2000) and Pitault et al. (1995).

The software ANSYS ${ }^{\circledR}$ CFX was used to model and simulate the FCC riser. An Eulerian-Eulerian approach along with a standard $k-\varepsilon$ turbulence model was applied in this study. The riser geometry and mesh domain are illustrated in Figure 2-a, and the cross-section, for better visualization, is shown in Figure 2-b. The total number of elements is over 80,000.

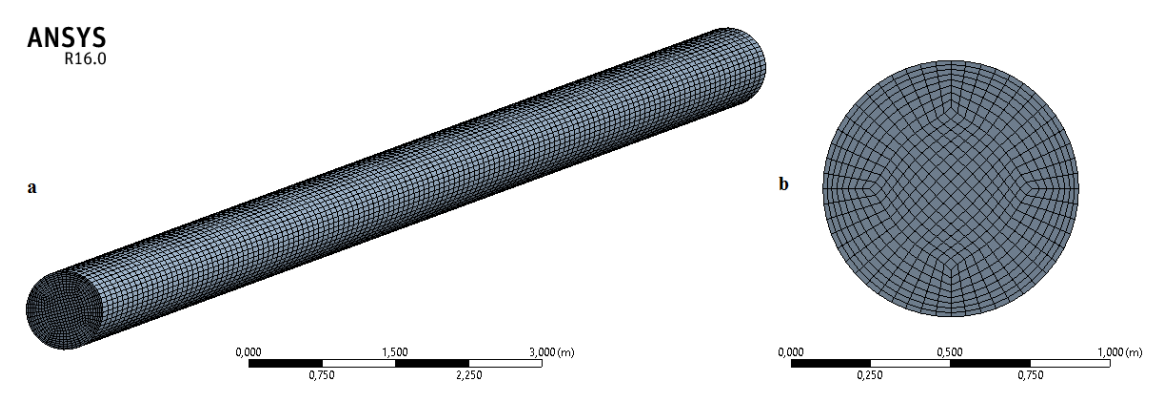

Figure 2 - a) Geometry and mesh domain. b) Cross-section

\section{RESULTS}

The results obtained for VGO, gasoline, light gas and coke mass fractions in the reactor exit for different temperatures are shown in Figure 3.

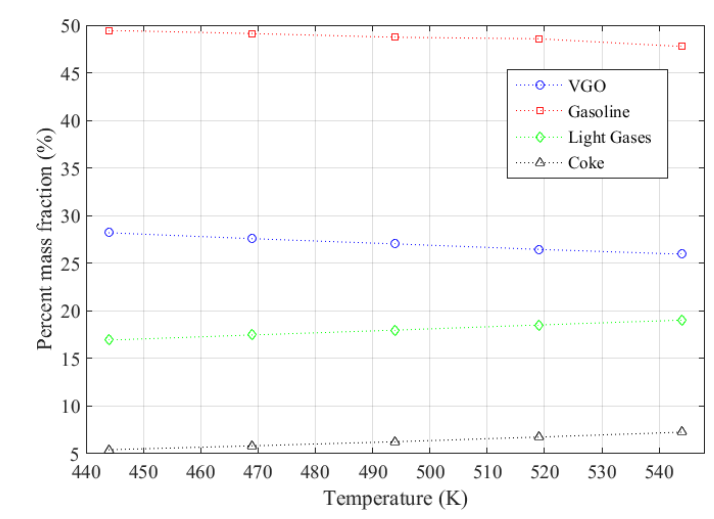

Figure 3 - Mass fraction of the lumps along the reactor.

It is observed that lower temperatures favor the conversion of VGO into gasoline, while the increase of temperature favors the secondary conversion of gasoline into light gases and coke. Table 2 shows the exit simulation results obtained for gasoline and coke mass fractions and temperature as well as the variations based on the plant data (at 494K). The observed variation of the exit temperature comparing plant and simulation data was lesser than $1 \%$. The values found for gasoline and coke mass fraction were also close to the experimental ones. 


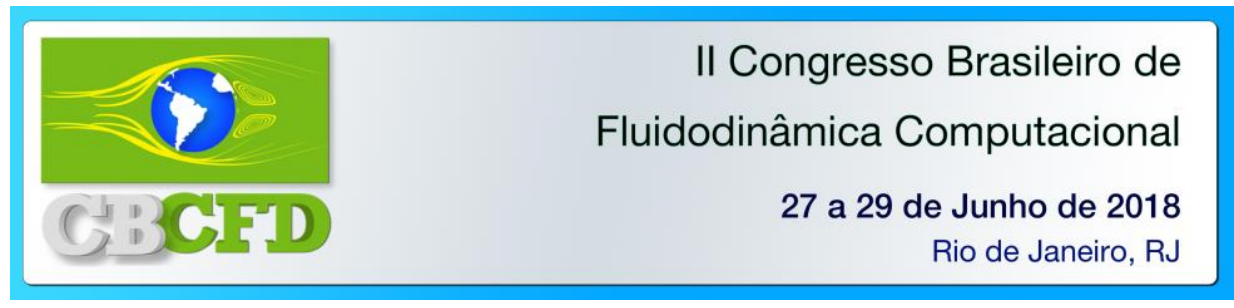

Table 2 - Simulation and plant data and the variation

\begin{tabular}{cccc}
\hline Variable at the riser exit & Simulation & Plant & Variation (\%) \\
\hline Gasoline mass fraction (\%) & 48,73 & 43,9 & 9,91 \\
Coke mass fraction (\%) & 6,26 & 5,8 & 7,35 \\
Temperature (K) & 801 & 795 & 0,75 \\
\hline
\end{tabular}

\section{CONCLUSIONS}

The simulation results are in accordance with the plant data available in the literature, which indicates that 4-lumps model adopted is adequate. The results showed that the conversion of VGO into gasoline is favored by lower temperatures, while the conversion reactions of gasoline into light gases and coke are favored by higher temperatures. With higher values of inlet temperature, greater amounts of converted VGO are achieved, and, as a secondary effect, the coke production is also increased, which can be seen as a disadvantage. A cost analysis is necessary to ensure which temperature provides the best operation.

\section{NOMENCLATURE}

\begin{tabular}{|c|c|c|c|}
\hline $\begin{array}{l}\mathrm{FCC} \\
\Phi_{i}\end{array}$ & $\begin{array}{l}\text { Fluid catalytic cracking } \\
\text { Catalyst activity factor }\end{array}$ & $E_{a_{j}}$ & $\begin{array}{l}\text { Activation energy of a reaction } \mathrm{j} \\
\left(\mathrm{J} \mathrm{mol}^{-1} \mathrm{~K}^{-1}\right)\end{array}$ \\
\hline$w_{C}$ & Coke mass fraction & $k_{j}^{o}$ & Pre-exponential factor $\left(s^{-1}\right)$ \\
\hline$C_{j}$ & Concentration of a component $j$ & VGO & Vacuum gas oil \\
\hline$C_{j_{o}}$ & $\begin{array}{l}\left(\mathrm{mol} \mathrm{L}^{-1}\right) \\
\text { Concentration of a reagent } \mathrm{j}\end{array}$ & $r_{j}$ & $\begin{array}{l}\text { Rate of consumption of a reagent } \mathrm{j} \\
\text { per unit volume of catalyst }\left(\mathrm{kg} \mathrm{s}^{-1}\right)\end{array}$ \\
\hline & $\left(\mathrm{mol} \mathrm{L}^{-1}\right)$ & $\mathrm{T}$ & Temperature $(\mathrm{K})$ \\
\hline $\begin{array}{l}k_{j} \\
R\end{array}$ & Velocity constant $\left(s^{-1}\right)$ & $\mathrm{T}^{\mathrm{o}}$ & Reference temperature (K) \\
\hline
\end{tabular}

\section{REFERENCES}

ALI, H.; ROHANI, S.; CORRIOU, J. P. Modelling and control of a riser type fluid catalytic cracking (FCC) unit. Trans IChemE, v. 75, p. 401-412, 1997.

GUPTA, A.; RAO, D. S. Model for the performance of a fluid catalytic cracking (FCC) riser. Chemical Engineering Science, v. 56, p. 4489-4503, 2001.

HAN, I. S.; CHUNG, C. B. Dynamic modeling and simulation of a fluidized catalytic cracking process. Part I: Process modeling. Chemical Engineering Science, v. 56, p. 1951-1971, 2011.

LEE, L.; CHEN, Y.; HUANG, T. Four-lump kinetic model for fluid catalytic cracking process. The Canadian Journal of Chemical Engineering, v. 67, p. 615-619, 1989.

PACHOVSKY, R. A.; WOJCIECHOWSKI, B. W. Theoretical interpretation of gas oil conversion data on an X-sieve catalyst. The Canadian Journal of Chemical Engineering, v. 49, p. 365-369, 1971.

PITAULT, I.; FORISSIER, M.; BERNARD, J. R. Determination de constantes cinetiques du craquage catalytique par la modelisation du test de microactivite (MAT). The Canadian Journal of Chemical Engineering, v. 73, p. 498-503, 1995. 